\title{
Hospital Infection and Disinfection
}

\author{
G.A.J. Ayliffe \\ Professor, Department of Medical Microbiology, \\ The Medical School, Birmingham University
}

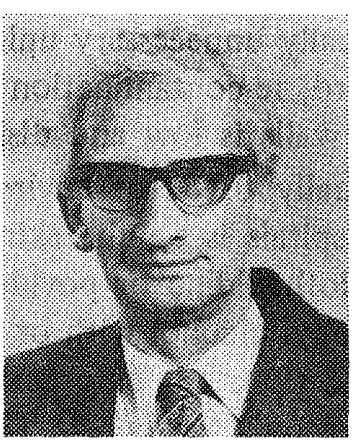

Hospital infection is a world-wide problem, although the incidence or prevalence in most countries is not known. In a prevalence survey made in the United Kingdom in 1980, involving 43 hospitals and 18,000 patients, 1 in 5 patients were found to have an infection and half of these infections were hospital-acquired. ${ }^{1)}$ The survey was carried out by medical microbiologists and infection control nurses. Urinary tract infection was the most common acquired infection (2.8\% of all patients), followed by wound infection (1.7\%) and lower respiratory tract infection (1.5\%). Gram-negative infections were the most common $(60.1 \%)$. Similar results have been obtained in other countries and it is likely that this is a common pattern throughout the world, although it is possible that third-world countries may show some differences. However, many infections are endogenous in origin and it is not known how many of these are preventable.

The role of equipment in hospital infection has become increasingly important and many items cannot be sterilized by conventional methods. Acquired urinary tract infection is commonly associated with indwelling catheterization, and lower respiratory tract infection with mechanical respiratory ventilation. Infection from equipment such as fibre-optic endoscopes is uncommon, but when it occurs it can be hazardous to the patient; infections have included pseudomonas in leukaemic patients and salmonellosis.

The risk of infection from equipment can be classified as 1) high risk, when the equipment comes into close contact with a break in the skin or mucous membrane, e.g. during surgery; 2 ) moderate or occasional risk - contact with intact skin or mucous membrane, e.g. gastroscopy, and 3) low risk - no direct contact with patient or his immediate surroundings, e.g. cleaning equipment, floors, etc. High risk equipment can usually be sterilized by heat or is disposable and will not be further considered. The main problems are complex, expensive items which are difficult to clean and often heat-labile, such as flexible fibre-optic endoscopes.

The common methods of sterilization and disinfection are well-known and only low temperature steam (LTS) with or without formaldehyde will be considered. ${ }^{2)}$ Disinfection with steam at low pressure, temperature $70-80^{\circ} \mathrm{C}$, is a more effective process than treating in water at that temperature; after processing equipment can be dried by a vacuum as in a conventional autoclave. If formaldehyde is added the process can be used to sterilize equipment which may be damaged at higher temperatures. Little residual formaldehyde remains after completion of the process and the equipment can be used immediately. Flexible fibre-optic endoscopes may be damaged by this process, and chemical disinfection is required if immediate use is required. Glutaraldehyde is the disinfectant most commonly used for this purpose, but other agents are as effective if used in a suitable cleaning and disinfection machine. ${ }^{3)}$ The following reductions of bacteria $\left(\log _{10}\right)$ in the channels of the gastroscope were obtained after cleaning and disinfection in an automatic machine during routine use: glutaraldehyde$3.33,70 \%$ alcohol -3.8 , povidone-iodine 3.6, quaternary ammonium/EDTA -3.4 , cleaning with neutral detergent - only 2.5 . The cycle time is about 6 mins, but this can be extended at the end of 
a session. Flexible fibre-optic endoscopes can be sterilized in ethylene oxide and machines are available which operate reliably and safely at $37^{\circ} \mathrm{C}$ and at low pressures. However, this process is not suitable for between-patient treatment due to the length of the cycle and the need for aeration.

Routine disinfection of the inanimate environment (e.g. low-risk areas - floors and walls) is usually unnecessary unless obviously contaminated with blood, pus or infectious materials. In a busy ward, re-contamination of floors after cleaning or disinfection occurs in 1-2 hours. Contamination of walls is low and disinfection is rarely required.4) Clear soluble phenolics and hypochlorites are usually used for environmental disinfection. However, the main use for chemical disinfectants in hospitals is on the skin of the operation site and the hands of the surgeon. Alcoholic solutions of chlorhexidine or povidone-iodine are used for disinfection of the operation site. $70 \%$ ethyl or $60 \%$ propyl alcohol with or without a disinfectant are the most effective agents for immediate hand disinfection, but chlorhexidine or povidone-iodine detergents are usually used for disinfection of the surgeon's hands. $\left.{ }^{5}, 6\right)$ The antiseptic-detergents produce a progressive reduction of organisms on the surgeon's hands and, particularly chlorhexidine, have a residual effect. Washing with an antiseptic detergent, without a brush, for 2-3 minutes, is adequate but it is important to ensure all surfaces of the hands are well-covered.

Methods for prevention of infection may be classified as: 1) established, for which good clinical evidence is available, e.g. closed drainage of urinary tract or ultra-clean air in joint prosthesis operations; 2) provisionally established, for which there is some evidence; 3) rational, consistent with our knowledge of bacteria, but which cannot be proven, and 4) rituals, methods which have little or no value. Disinfection as a method of prevention of infection is often difficult to classify, but for items of intermediate or occasional risk, it could usually be classified as provisionally established or rational, whereas for low risk items, e.g. routine cleaning of floors, it is usually a ritual.

\section{References}

1. Meers, P.D., Ayliffe, G.A.J., Emmerson et al. (1981) Report on national survey of infection in hospitals 1980. J. Hosp. Infect. 2 (Suppl.)

2. Alder, V.G., Gingell, J.C. \& Mitchell, J.P. (1971) Disinfection of cystoscopes by sub-atmospheric steam and steam formaldehyde at $80^{\circ} \mathrm{C}$. Brit. med. J. 3 , 677-680

3. Babb, J.R., Bradley, C.R., Deverill, C.E.A., Ayliffe, G.A.J. \& Melikian, V. (1981) Recent advances in the cleaning and disinfection of fibrescopes. J. Hosp. Infect. 2, 329-340

4. Ayliffe, G.A.J., Collins, B.J.L., Babb, J.R., Lowbury, E.J.L. \& Lilly, H.A. (1967) Ward floors and other surfaces as reservoirs of hospital infection. J. Hyg. (Lond.) 65, 515.

5. Lowbury, E.J.L. (1973) Skin preparation for operation. J. Hosp. Med. 10, 627-634

6. Ayliffe, G.A.J. (1980) The effect of antibacterial agents on the skin. J. 